\author{
Original
}

\title{
Annealing effect on the mechanical properties of ultrafine $\mathrm{WC}-\mathrm{Co}$ materials
}

\author{
Yigao Yuan*, Lanping Fu, Jianpeng Li \\ College of Mechanical Engineering, Donghua University, 201620 Shanghai, China \\ Received 6 July 2016; accepted 21 March 2017 \\ Available online 26 August 2017
}

\begin{abstract}
In dry machining, the tool-chip interface temperature is a critical factor affecting the engineering performance of WC-Co tools. As the temperature variation of the cutting tool in dry machining is similar to that in annealing process, the effect of tool-chip interface temperature on the mechanical properties of cutting tool materials in dry machining can be studied by means of annealing experiment. In this paper, a series of annealing experiments of ultrafine-grained WC-Co materials were conducted, and the effects of the annealing temperature and holding time on the mechanical properties of WC-Co materials, including flexural strength, hardness and fracture toughness, were investigated. The results show that under the experimental conditions, the annealing temperature dominates the mechanical properties of WC-Co materials. The flexural strength and fracture toughness of the ultrafine-grained WC-Co materials decrease in different extent with increasing of annealing temperature, whereas the hardness does not change obviously. The measurements of the microstructures and residual stresses revealed that the deterioration of mechanical properties of WC-Co materials after annealing can be attributed to the relaxation of compressive residual stress.

(C) 2017 Universidad Nacional Autónoma de México, Centro de Ciencias Aplicadas y Desarrollo Tecnológico. This is an open access article under the CC BY-NC-ND license (http://creativecommons.org/licenses/by-nc-nd/4.0/).
\end{abstract}

Keywords: Ultrafine cemented carbides; Annealing; Mechanical properties; Residual stress

\section{Introduction}

With the rapid development of modern manufacturing industry, high speed machining and precision machining have been used extensively in structural parts manufacturing. Additionally, dry machining without cutting fluid or with minimal quantity of lubricant (MQL) can obviously reduce the harm of coolants to the environment, which is produced mainly in wet machining (Hadad \& Sharbati, 2016). In view of the above reasons, it is very important for cutting tools to have good tribological and thermal properties at severe machining conditions.

In the past decades, the ultrafine-grained WC-Co cemented carbides with grain size less than $0.6 \mu \mathrm{m}$ have been widely used as cutting tools in machining processes, owing to their high hardness and wear resistance (Jia, Fischer, \& Gallois, 1998; Shi, Shao, Duan, Yuan, \& Lin, 2005). In dry machining processes, cutting tools are generally subjected to severe mechanical and thermal conditions, and the heat produced during the machining

\footnotetext{
* Corresponding author.

E-mail address: yuanyg@dhu.edu.cn (Y. Yuan).

Peer Review under the responsibility of Universidad Nacional Autónoma de
} México. process is critical for tool life and workpiece surface quality (Nouari, List, Girot, \& Coupard, 2003). According to previous works (Ezugwu \& Wang, 1997; Jiang, 2005), the temperature along the tool-chip interface can reach as high as $1000^{\circ} \mathrm{C}$ in cutting hard-to-machine materials, such as titanium alloys and nickel alloys. Such a high temperature will result in not only tool wear such as abrasion, adhesion and diffusion, but also the deterioration of mechanical properties of cutting tool materials. List et al. (2005) described tool wear mechanism in dry machining of a common Al-Cu alloy with an uncoated WC-Co tool. They found that tool wear behavior is primarily dependent on toolchip interface temperature. At conventional cutting conditions, the interface temperature is low $\left(150-180^{\circ} \mathrm{C}\right)$ and the adhesion of built-up edge (BUE) is principally mechanical, continuous sliding of BUE fragments between tool and chip causes tool wear increasingly. On the contrary, at severe cutting conditions, temperature is higher $\left(245-310^{\circ} \mathrm{C}\right)$ and mechanisms of tool wear involve chemical action and diffusion. Kagnaya, Boher, Lambert, Lazard, and Cutard (2009) have studied the wear mechanism of WC-Co cutting tools from high-speed tribological tests. They found that WC-Co tribological pins exhibit different wear mechanisms: abrasion, adhesion, transgranular WC micro-cracking and WC/WC debonding. At low sliding 
speeds, the wear mechanisms of the pin include plastic deformation and microcracking of $\mathrm{WC}$ grains, fragmentation and debonding of WC grains and polishing of the pin contact surface. But, at high sliding speeds, $88.5 \%$ of the mechanical energy dissipated in the pin is transformed into thermal energy and adhesion plays an important part in the tool wear mechanisms.

Although there has been considerable research reported over the last two decades on the correlation between tool-chip interface temperature and the wear behavior of $\mathrm{WC}-\mathrm{Co}$ tools in dry machining, the research on the influence of tool-chip interface temperature on the mechanical properties of $\mathrm{WC}-\mathrm{Co}$ materials, to the best of the author's knowledge, has not been deeply reported in the open literature up to now. In fact, variation of temperature of the cutting tool in dry machining is similar to that in annealing process, i.e., the temperature of cutting tool gradually rises at the beginning of machining, and then remains at a stable temperature for a period of time, finally decreases slowly to room temperature after machining, thus the effect of tool-chip interface temperature on the mechanical properties of cutting tool materials in dry machining can be studied by means of annealing experiments of WC-Co materials. In the present study, a series of annealing experiments of the ultrafinegrained WC-Co materials were conducted to evaluate the effect of annealing temperature and holding time on the mechanical properties of the $\mathrm{WC}-\mathrm{Co}$ materials.

\section{Experimental}

\subsection{Materials and sample preparation}

The materials used in this work were ultrafine-grained WC-Co cemented carbides with nominal composition of $12 \mathrm{wt} . \% \mathrm{Co}$ and mean WC grain size of $0.4 \mu \mathrm{m}$. The preparation of samples was carried out as follows: The WC-12 wt.\%Co mixed powder was milled in alcohol for $72 \mathrm{~h}$ in a ball mill. The milled powder was dried at $95^{\circ} \mathrm{C}$ and then cold pressed at $200 \mathrm{MPa}$ into green compacts of $21 \mathrm{~mm} \times 6.5 \mathrm{~mm} \times 5.25 \mathrm{~mm}$ in dimensions. Finally, the green compacts were sintered in vacuum at $1400{ }^{\circ} \mathrm{C}$ for $1 \mathrm{~h}$, and then the hot isostatic pressing (HIP) technology was used to minimize pores, considering the fact that mechanical properties of the $\mathrm{WC}-\mathrm{Co}$ materials are very sensitive to porosity levels. The optical micrograph of polished surface of the ultrafine-grained WC-Co materials is shown in Figure 1. As can be seen from Figure 1, the sample is dense enough and porosities can be negligible.

After sintering, all samples were ground to dimensions using a resin-bonded diamond straight wheel and a M7120 surface grinder, subsequently were polished with $10 \mu \mathrm{m}$ diamond paste to achieve dimensional accuracy as well as good surface finishes. It should be noted that surface roughness $\left(R_{\mathrm{a}}\right)$ of a specimen must be less than $0.4 \mu \mathrm{m}$, or it would not be used for this study. The dimensions of the wheels were $250 \mathrm{~mm}$ in diameter, $12 \mathrm{~mm}$ in width, and $8 \mathrm{~mm}$ in the thickness of the diamond layer. Grinding was carried on the $21 \mathrm{~mm} \times 6.5 \mathrm{~mm}$ surface of the samples. Prior to beginning the experiments, the samples were glued on a steel plate with hot wax. Then, the steel plate was fixed on the grinding machine as parallel as possible with the abrasive wheel to avoid

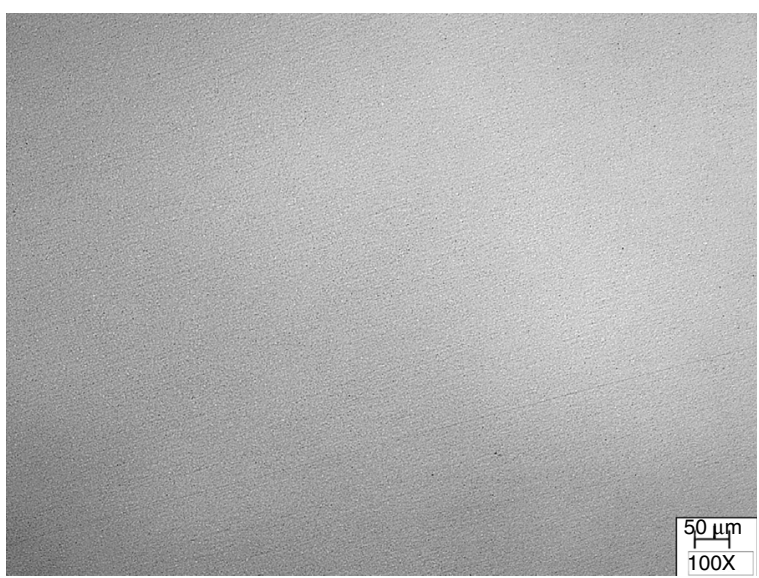

Fig. 1. Surface morphology of the materials investigated.

Table 1

Grinding parameters used during grinding

\begin{tabular}{llll}
\hline Wheel speed, $\mathrm{m} / \mathrm{s}$ & $\begin{array}{l}\text { Table speed } \\
\text { (workpiece), } \\
\mathrm{m} / \mathrm{min}\end{array}$ & $\begin{array}{l}\text { Average size of the } \\
\text { abrasive grains, } \mu \mathrm{m}\end{array}$ & $\begin{array}{l}\text { Depth of cut, } \\
\mu \mathrm{m}\end{array}$ \\
\hline 30 & 109 & 10
\end{tabular}

Table 2

Annealing heat treatment parameters.

\begin{tabular}{llll}
\hline $\begin{array}{l}\text { Annealing } \\
\text { temperature, }{ }^{\circ} \mathrm{C}\end{array}$ & Holding time, min & $\begin{array}{l}\text { Heating rate, } \\
{ }^{\circ} \mathrm{C} / \mathrm{min}\end{array}$ & $\begin{array}{l}\text { Cooling } \\
\text { method }\end{array}$ \\
\hline $\begin{array}{l}300,500,700,900 \\
\text { and } 1100\end{array}$ & 5 & $\begin{array}{l}\text { Furnace } \\
\text { cooling }\end{array}$ \\
900 & $10,20,30,40$ and 80 & \\
\hline
\end{tabular}

a After holding the annealing temperature for a prescribed time, then turning off the power, the samples were cooled slowly to room temperature in the furnace.

a variation of depth of cut over the surface of the sample. Wateroil emulsion was used as a coolant during the grinding process to avoid burning out and thermal damage. The grinding parameters were used listed in Table 1.

After grinding, all samples were ultrasonically cleaned with acetone, and then some samples were annealed in a vacuum sintering furnace. In this study, the range of annealing temperatures was selected from 300 to $1100{ }^{\circ} \mathrm{C}$, which is based on the highest temperature of tool-chip interface in dry machining of different materials provided in (Ezugwu \& Wang, 1997; Jiang, 2005; List et al., 2005). During the annealing experiments, various parameters were used as listed in Table 2.

\subsection{Characterization of mechanical properties}

The surfaces of samples before and after annealing were investigated using an X-ray microstress analyzer (LXRD, Canada) to measure the residual surface stresses by $\sin ^{2} \psi$ method. The stresses in the surface of samples were measured using the (301) reflection of WC with $\mathrm{Cu}$ Ka radiation. The full width half mean peak position was determined for a range of $\psi$ 
angles $\left(-25^{\circ},-16.78^{\circ},-5.85^{\circ}, 0^{\circ}, 5.85^{\circ}, 16.78^{\circ}\right.$ and $\left.25^{\circ}\right)$. The residual stress measurements were repeated six times on each sample to improve accuracy and to obtain the mean value.

Mechanical properties of the specimens before and after annealing, including flexural strength, hardness and fracture toughness, were measured and compared. The flexural strength was measured on the ground specimens by universal testing machines according to ASTM B406 standard. The hardness was measured by Vickers hardness tester with a load of $30 \mathrm{kgf}$ according to ASTM B294 standard. The fracture toughness was obtained by measuring the crack length generated at the vertices of Vickers indentation using the equation (Schubert, Neumeister, Kinger, \& Lux, 1998):

$K_{1 C}=0.0028\left(\frac{H \times P}{\sum L}\right)^{1 / 2}$

where $H$ is the indentation hardness $\left(\mathrm{N} / \mathrm{mm}^{2}\right), P$ is the indentation load $(\mathrm{N})$, and $\sum L$ is the sum of crack lengths $(\mathrm{mm})$. At least ten specimens were tested for the measurements of each property, and the average value was finally determined.

In addition, microstructure of samples before and after annealing were also investigated by scanning electron microscope (SEM) and X-ray diffraction (XRD) to find whether any growth of $\mathrm{WC}$ grain or phase transformation of the Co phase has taken place during annealing. The average grain size of WC was measured based on the backscattered electron (BSE) images of the microstructure and IMAGEJ image analysis software (Yuan, Zhang, Ding, \& Ruan, 2013). The Co phase composition of the specimens was detected by X-ray diffractometry with $\mathrm{Cu}$ Ka radiation. In order to decrease WC phase diffraction peak interference to Co-phase X-ray diffraction analysis, specimens were etched by Murakami's reagent $\left(\mathrm{K}_{3} \mathrm{Fe}(\mathrm{CN})_{6}: \mathrm{KOH}: \mathrm{H}_{2} \mathrm{O}=1: 1: 10\right)$ for $24 \mathrm{~h}$ before XRD examination, considering that Co content is lower in WC-Co materials.

\section{Results and discussion}

\subsection{Effect of annealing temperature}

Cemented carbides are difficult to machine because of their extreme hardness, so grinding with diamond wheels to date is still the most important machining method in the industry for various WC-Co materials. In grinding, due to the mechanical interactions of diamond abrasives with the carbide materials, significant residual stress, namely, grinding-induce residual stress or grinding residual stress was generated near the ground surface of sample. The existing work has shown that the grinding-induce residual stress in the ground carbide materials is compressive in WC and tensile in Co (Hegeman, De Hosson, \& De With, 2001; Yin et al., 2004), and it can be relieved effectively by annealing heat treatment (Yang, Odén, Johansson-Jõesaar, \& Llanes, 2014). Relaxation degree of residual stresses can be defined as the relaxation rate, and it can be expressed as (Yuan \& Xu, 2012):

$\sigma_{r e l}^{r}=\frac{\sigma_{b}^{r}-\sigma_{a}^{r}}{\sigma_{b}^{r}} \times 100 \%$ where $\sigma_{r e l}^{r}$ is the relaxation rate of residual stresses, $\sigma_{b}^{r}, \sigma_{a}^{r}$ are the magnitudes of residual stresses in ground surface before and after treated, respectively.

After annealed at $300,500,700,900$ and $1100{ }^{\circ} \mathrm{C}$ with the holding time of $30 \mathrm{~min}$ respectively, the variations of relaxation rate of residual stresses, flexural strength, hardness and fracture toughness of ultrafine-grained WC-Co materials are shown in Figure 2. It can be clearly seen that the annealing temperatures have a significant influence on the relaxation rate of residual stresses and flexural strength of the ultrafine-grained WC-Co materials. Relaxation rate of residual stresses increases almost linearly with increasing of annealing temperatures from 300 to $900^{\circ} \mathrm{C}$, then decreases suddenly at temperature over $900{ }^{\circ} \mathrm{C}$ (as shown in Fig. 2a). By contrast, flexural strength of the ultrafine-grained WC-Co materials decreases obviously with increasing of annealing temperatures from 300 to $900^{\circ} \mathrm{C}$. Only when annealing temperature exceeds $900^{\circ} \mathrm{C}$, will flexural strength rebound slightly but still lower than that of samples untreated (as shown in Fig. 2b).

It can also be seen that the fracture toughness of the samples after annealing decreased slightly compared with that of samples untreated, but it varies slightly with annealing temperature (as shown in Fig. 2c). As to hardness of WC-Co materials, it seems that the annealing temperatures have no obvious influence. The measurements of the hardness show that there is only a little difference between the samples of before and after annealing (as shown in Fig. 2d).

\subsection{Effect of holding time}

The ground samples were annealed at $900{ }^{\circ} \mathrm{C}$ with the holding time of 10, 20, 30, 40 and 80 min respectively. Figure 3 displays the variations of relaxation rate of residual stresses, flexural strength, hardness and fracture toughness of ultrafine-grained WC-Co materials with the holding time. As seen from Figure 3, although there are slight decrease in the flexural strength and fracture toughness of the annealed samples in comparison with that of samples untreated, no obvious difference were observed between the different holding times. Also, the measurements show that the holding time has no obvious influence on the residual stresses and hardness of the ultrafine-grained WC-Co materials. These results suggest that annealing temperature during annealing process may dominate the mechanical properties of WC-Co materials, instead of holding time.

\subsection{Microstructure}

Figure 4 shows the $\mathrm{X}$-ray diffraction patterns of the samples before and after annealing. Comparing with the $\mathrm{X}$-ray patterns of the untreated sample, it can be clearly seen that the characteristic diffraction peaks of the annealed ones have no obvious change, whether at annealing temperature $900^{\circ} \mathrm{C}$ or at $1100^{\circ} \mathrm{C}$, indicating no phase transformation of Co from $\alpha \rightarrow \varepsilon$ occurs during annealing progress.

Figure 5 reveals the microstructures of the ultrafine-grained WC-Co materials before and after annealing, in which the white crystals are the WC phase, and the black contrast regions 

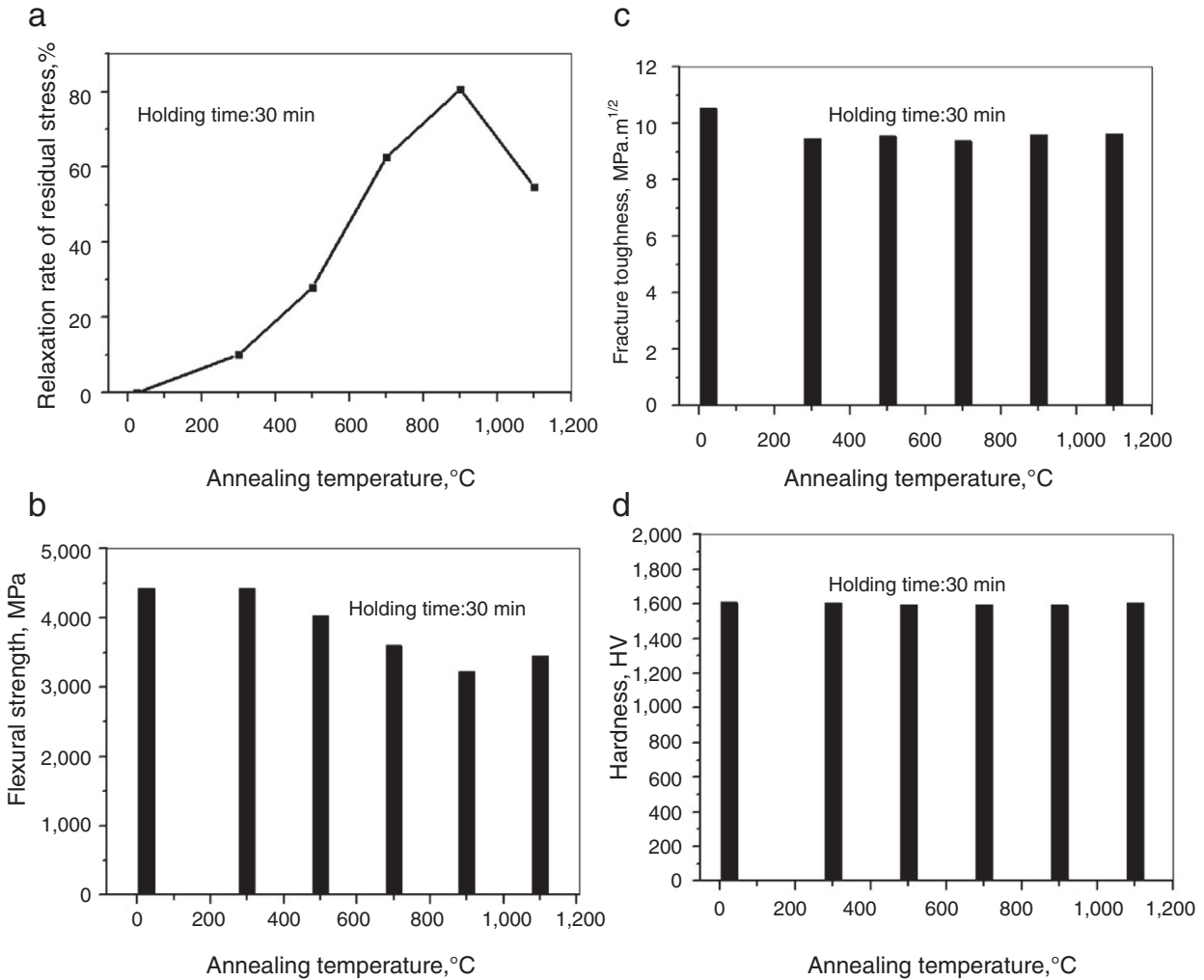

Fig. 2. Variation of mechanical properties of WC-Co materials with annealing temperatures. (a) Residual stress, (b) flexural strength, (c) fracture toughness and (d) hardness.

a

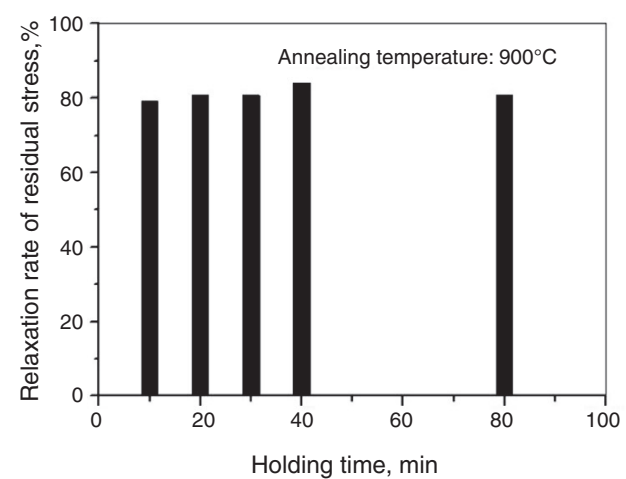

b

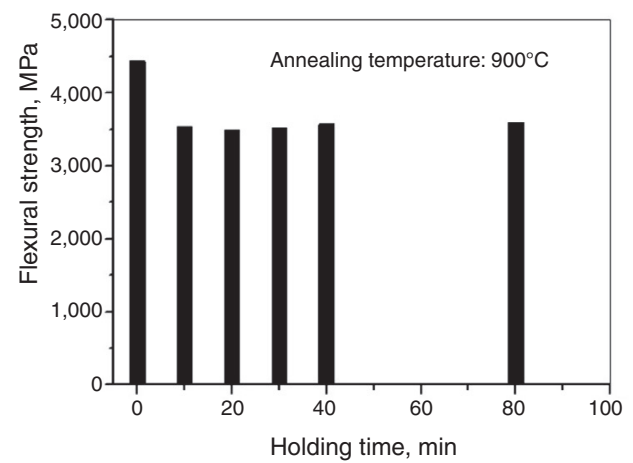

C

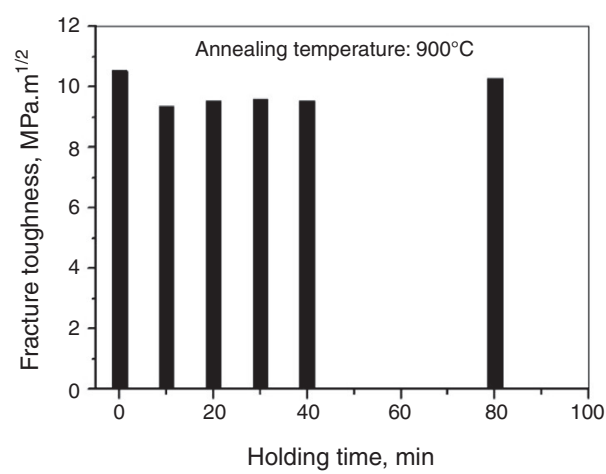

d

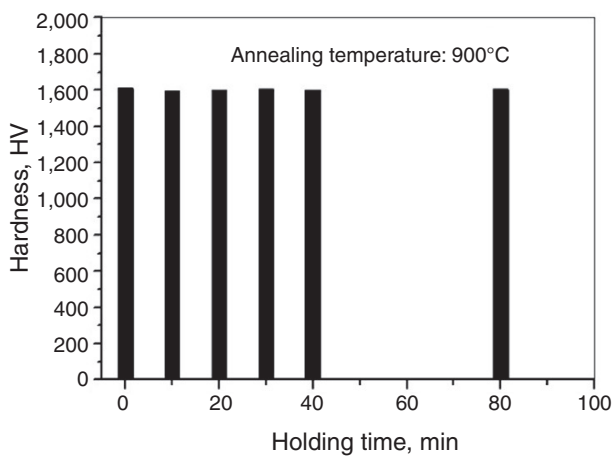

Fig. 3. Mechanical properties of WC-Co materials versus holding time. (a) Residual stress, (b) flexural strength, (c) fracture toughness and (d) hardness. 


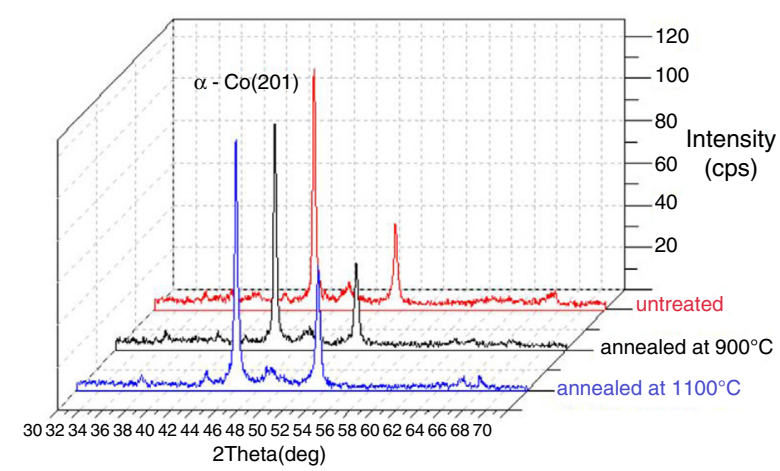

Fig. 4. X-ray diffraction spectrum of ultrafine cemented carbides.

Table 3

Measurement results of WC grain sizes in samples.

\begin{tabular}{ll}
\hline Samples & Average grain size of $\mathrm{WC}(\mu \mathrm{m})$ \\
\hline $\begin{array}{l}\text { Before annealing } \\
\text { After annealing }\end{array}$ & 0.465 \\
$\quad \begin{array}{l}\text { Annealing temperature: } 900^{\circ} \mathrm{C} \text {, holding } \\
\text { time: } 80 \mathrm{~min}\end{array}$ & 0.497 \\
$\begin{array}{l}\text { Annealing temperature: } 1100^{\circ} \mathrm{C} \text {, holding } \\
\text { time: } 80 \mathrm{~min}\end{array}$ & 0.526 \\
\hline
\end{tabular}

between the WC grains are the cobalt binder phase. The measurement results of WC grain sizes in samples before and after annealing are listed in Table 3. It can be seen that the WC grain sizes of the annealed samples are larger than that of the untreated ones, but the difference is quite small. It illustrates that the WC grains have a tendency to grow up during annealing process, but the growth rate is very small.

In general, the mechanical properties of the $\mathrm{WC}-\mathrm{Co}$ materials are primarily dependent on their microstructural parameters, i.e., cobalt (Co) content and WC grain size. With smaller WC particle size at fixed Co content, WC-Co has a higher hardness, higher flexural strength and lower toughness. Conversely, WC-Co would have a higher toughness, lower hardness and lower flexural strength (Akhtar, Humail, Askari, Tian, \& Guo, 2007; Okamoto, Nakazono, Otsuka, Shimoitani, \& Takada, 2005). According to the measurements of microstructure of the samples before and after annealing, and taking into account the stability of Co content in WC-Co materials during vacuum annealing, the flexural strength and hardness of ultrafine-grained WC-Co materials after annealing should decrease slightly, while the fracture toughness should increase slightly due to the slight growth of WC grain sizes. However, our experiments show that after annealing process, the flexural strength of ultrafine-grained WC-Co materials decreases significantly and the fracture toughness decreases slightly, this is not in accordance with the theories mentioned above, indicating that some other factors may play important role in affecting the mechanical properties of the WC-Co materials during annealing.

Besides microstructural parameters, the nature and magnitude of residual surface stress have also significant effects on the mechanical properties of WC-Co materials. By inhibiting WC particle pull-out and by introducing stresses that close crack tips, compressive surface stresses can retard crack initiation a

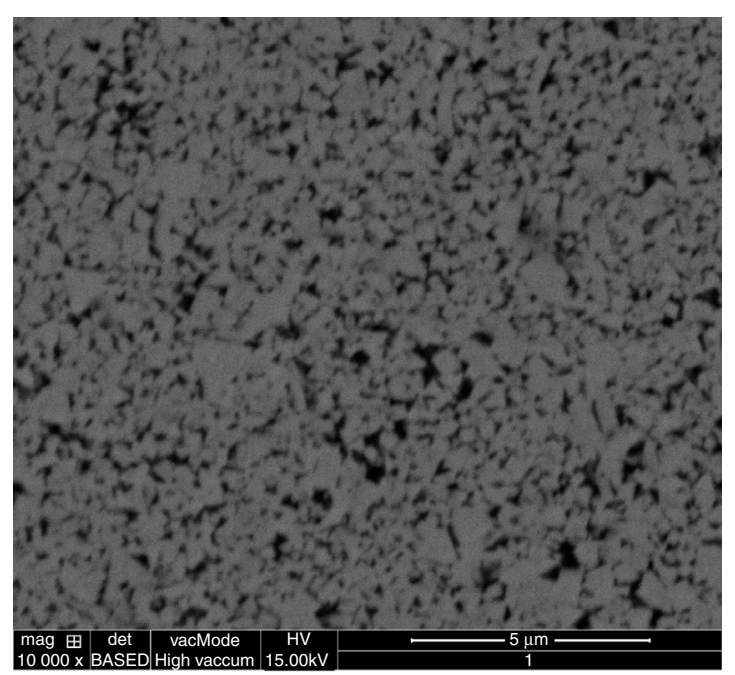

b

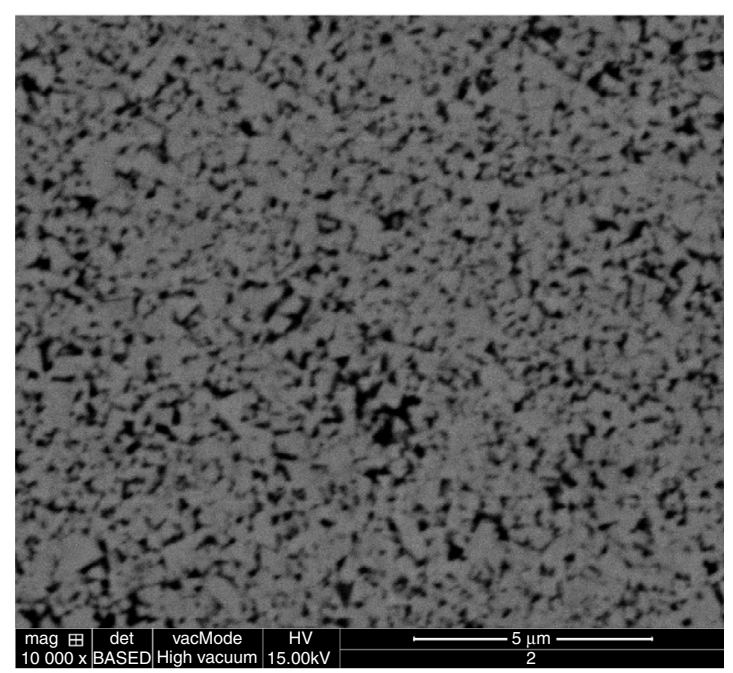

C

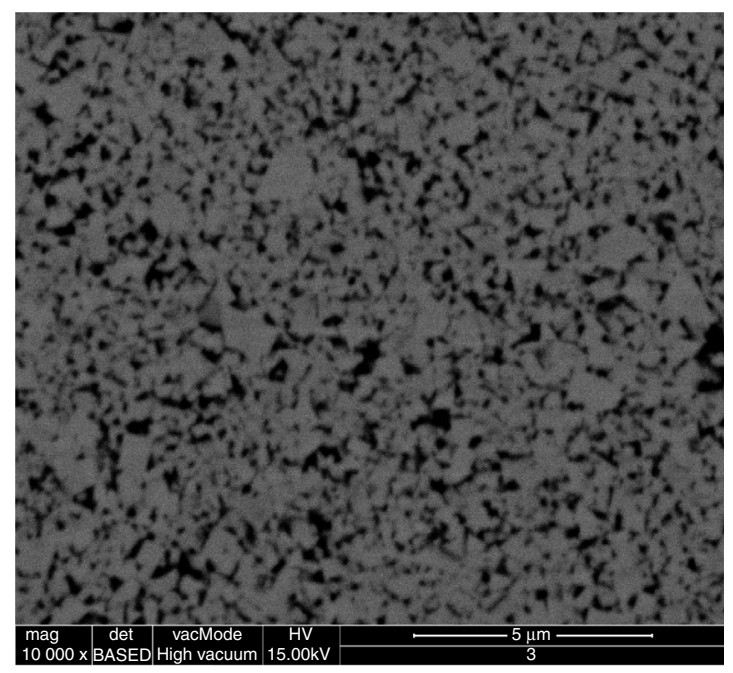

Fig. 5. SEM backscattered electron images of the materials investigated. (a) Untreated, (b) annealed at $900^{\circ} \mathrm{C}, 80 \mathrm{~min}$ and (c) annealed at $1100^{\circ} \mathrm{C}, 80 \mathrm{~min}$. 
and propagation, and thus increasing the fracture toughness of WC-Co materials (Lambropoulos, 1991). Meanwhile, a compressive residual stress can also be applied to improve the strength of ground specimens, since the total strength $S$ can be estimated by Xu, Jahanmir, and Ives (1997):

$S=S_{G}+S_{\sigma}$

where $S_{G}$ is the strength of the material governed by intrinsic flaws only, and $S_{\sigma}$ is the extra stress that must be added to compensate for compressive residual stress.

From Figure 2a, the relaxation rate of residual stresses increases almost linearly with increasing of annealing temperatures from 300 to $900{ }^{\circ} \mathrm{C}$, that is to say, the magnitudes of surface compressive residual stress of annealed samples decrease quickly with increasing of annealing temperatures from 300 to $900{ }^{\circ} \mathrm{C}$ compare with that of samples untreated. According to formula (3), the flexural strength of ultrafine-grained WC-Co materials after annealing will decrease significantly with increasing of annealing temperatures, which is just the measured result shown in Figure 2b. Relaxation rate of residual stresses of WC-Co materials decreases obviously at annealing temperature above $900{ }^{\circ} \mathrm{C}$ may attribute to residual thermal stress, induced by larger temperature gradient upon cooling from annealing temperature back to room temperature. Accordingly, the flexural strength of WC-Co materials after annealing at $1100{ }^{\circ} \mathrm{C}$ rebounds slightly. Similarly, due to relaxation of compressive residual stresses, the fracture toughness of $\mathrm{WC}-\mathrm{Co}$ materials after annealing decreases slightly.

The relaxation process of grinding residual stress in $\mathrm{WC}-\mathrm{Co}$ alloys would be completed in a short period of time, for the size of samples was small. As a result, holding time was found to have little influence on the relaxation rate of residual stresses. Accordingly, the mechanical properties of ultrafine WC-Co materials after annealing have no obvious change under different holding time conditions.

\section{Conclusion}

In this study, the effect of annealing heat treatment on the mechanical properties of ultrafine-grained WC-Co materials was examined through a series of annealing experiments. It was found that under the condition of this study, the annealing temperature plays an important part on the mechanical properties of WC-Co materials, but the influence of holding time is relatively small. The flexural strength and fracture toughness of the ultrafine-grained WC-Co materials decrease in different extent with increasing of annealing temperature, and the hardness almost remain unchanged during annealing.

From the investigation of microstructures and residual stresses of WC-Co materials, it can be found that the deterioration of mechanical properties of $\mathrm{WC}-\mathrm{Co}$ materials after annealing treatment can be attributed to the relaxation of compressive residual stress.

\section{Conflict of interest}

The authors have no conflicts of interest to declare.

\section{Acknowledgement}

This work is supported by Shanghai Natural Science Foundation (No. 13ZR1401300).

\section{References}

Akhtar, F., Humail, I. S., Askari, S. J., Tian, J., \& Guo, S. (2007). Effect of WC particle size on the microstructure, mechanical properties and fracture behavior of $\mathrm{WC}-(\mathrm{W}, \mathrm{Ti}, \mathrm{Ta}) \mathrm{C}-6 \mathrm{wt} \%$ Co cemented carbides. International Journal of Refractory Metals \& Hard Materials, 25(5-6), 405-410.

Ezugwu, E. O., \& Wang, Z. M. (1997). Titanium alloys and their machinability-A review. Journal of Materials Processing Technology, 68(3), 262-274

Hadad, M., \& Sharbati, A. (2016). Thermal aspects of environmentally friendlyMQL grinding process. Procedia CIRP, 40, 509-515.

Hegeman, J. B. J. W., De Hosson, J. Th. M., \& De With, G. (2001). Grinding of WC-Co hardmetals. Wear, 248(1-2), 187-196.

Jia, K., Fischer, T. E., \& Gallois, B. (1998). Microstructure, hardness and toughness of nanostructured and conventional WC-Co composites. Nanostructured Materials, 10(5), 875-891.

Jiang, H. (2005). A cobalt diffusion based model for predicting crater wear of carbide tools in machining titanium alloys. Journal of Engineering Materials \& Technology, 127(1), 136-144.

Kagnaya, T., Boher, C., Lambert, L., Lazard, M., \& Cutard, T. (2009). Wear mechanisms of WC-Co cutting tools from high-speed tribological tests. Wear, 267(5), 890-897.

Lambropoulos, J. C. (1991). Toughening and crack tip shielding in brittle materials by residually stressed thin films. Journal of Vacuum Science \& Technology A - Vacuum Surfaces \& Films, 9(4), 2503-2509.

List, G., Nouari, M., Géhin, D., Gomez, S., Manaud, J. P., \& Le Petitcorps, Y. (2005). Wear behaviour of cemented carbide tools in dry machining of aluminium alloy. Wear, 259(7-12), 1177-1189.

Nouari, M., List, G., Girot, F., \& Coupard, D. (2003). Experimental analysis and optimisation of tool wear in dry machining of aluminium alloys. Wear, 255(7-12), 1359-1368.

Okamoto, S., Nakazono, Y., Otsuka, K., Shimoitani, Y., \& Takada, J. (2005). Mechanical properties of WC/Co cemented carbide with larger WC grain size. Materials Characterization, 55(4-5), 281-287.

Schubert, W. D., Neumeister, H., Kinger, G., \& Lux, B. (1998). Hardness to toughness relationship of fine-grained WC-Co hardmetals. International Journal of Refractory Metals \& Hard Materials, 16(2), 133-142.

Shi, X. L., Shao, G. Q., Duan, X. L., Yuan, H. Z., \& Lin, H. H. (2005). Mechanical properties, phases and microstructure of ultrafine hardmetals prepared by WC-6.29Co nanocrystalline composite powder. Materials Science \& Engineering A, 392(1-2), 335-339.

Xu, H. H., Jahanmir, S., \& Ives, L. K. (1997). Effect of grinding on strength of tetragonal zirconia and zirconia-toughened alumina. Machining Science and Technology, 1(1), 49-66.

Yang, J., Odén, M., Johansson-Jõesaar, M. P., \& Llanes, L. (2014). Grinding effects on surface integrity and mechanical strength of WC-Co cemented carbides. Procedia CIRP, 13, 257-263.

Yin, L., Spowage, A. C., Ramesh, K., Huang, H., Pickering, J. P., \& Vancoille, E. Y. J. (2004). Influence of microstructure on ultraprecision grinding of cemented carbides. International Journal of Machine Tools \& Manufacture, 44(5), 533-543

Yuan, Y. G., \& Xu, C. H. (2012). Influence of cryogenic treatment on grinding residual stress of WC-Co cemented carbides. Advanced Materials Research, 538-541, 1746-1750

Yuan, Y. G., Zhang, X. X., Ding, J. J., \& Ruan, J. (2013). Measurement of WC grain size in ultrafine grained WC-Co cemented carbides. Applied Mechanics \& Materials, 278-280, 460-463. 